\title{
REVIEW PAPER ON INFLUENCE OF STONE PROCESSING DUST ON MECHANICAL, DURABILITY AND SUSTAINABILITY OF CONCRETE
}

\author{
Abdul Ghaffar, Yogesh Kushwaha, Niraj Baramwar, Vikrant Lad, Rupal Janbandhu \\ Department of Civil Engineering \\ J D College of Engineering and Management, Nagpur, Maharashtra, India
}

\begin{abstract}
In current scenario structures are the most important part of human civilization. Due to increase in construction activities the demand of concrete also increased. In construction activities concrete is widely used material among all building materials. Concrete requires an abundant quantity of natural sand as a fine aggregate. Natural resources are on the verge of extinction. Apart from this stone dust generated from stone quarries which are hazardous to the environment. Stone dust generated from stone quarries is another option as a fine aggregate. Therefore this paper is a review of some research papers on quarry waste. In this research work, fine aggregate is partially or fully replaced by a stone processing dust to analyze the various properties of concrete.
\end{abstract}

Keywords - Stone Processing Dust (SPD), Impact energy, Embodied energy.

\section{INTRODUCTION}

Stone was one of the first materials used to make tools and buildings. The stone processing dust is a by-product of stone and obtained from the quarry. India is the third-largest country in the production of stone. During the production of stone, almost $30 \%$ of its mass is lost in the form of dust and estimated that 175 million tons of quarry waste are produced each year. This waste material is hazardous to human life. The main problem is to decompose this hazardous waste material which is responsible for environmental pollution. It is seen that these types of hazardous material remain unchanged for hundreds of years without any deterioration and also it is not decomposed by any artificial techniques.

SPD is an alternative material whose potential as a fine aggregate has been investigated in hundreds of years. Disposal of stone dust in concrete construction is one of the most efficient ways of hazardous waste management. The SPD can help to fill the pores of concrete which enhances the property of concrete structure. The waste material used in this research paper is stone processing dust in concrete.

\section{LITERATURE RIVIEW}

Trilok Gupta et at.[1] stated that Stone Processing Dust (SPD) can be used in concrete as a partial replacement to fine aggregate. Stone Processing Dust (SPD) is the by-product of stone which is obtained from quarry during the production of stones and aggregate. In this experiment, the Stone processing dust (SPD) is used having a size less than 75 microns is kept below $10 \%$. The natural sand is replaced in the variation of $0 \%, 10 \%, 20 \%, 30 \%, 40 \%, 50 \%, 60 \%, 70 \%, 80 \%, 90 \%$ \& $100 \%$ by Stone processing dust (SPD) and observe its influence on compressive, flexural strength, modulus of elasticity, impact energy, resistance to abrasion and water penetration.

Tests were carried out as per BIS 516[18], Compression test at7, 28, and 90 days were carried out on $100 \times 100 \times 100$ $\mathrm{mm}$ concrete cubes and flexural strength test at 7 and 28 days was carried out on $100 \times 100 \times 500 \mathrm{~mm}$ beams. As per ASTM C469[19] static modulus of elasticity was evaluated on cylindrical specimens $(150 \mathrm{~mm}$ diameter and 300 heights for 28 days curing) also the abrasion resistance tests were carried out as per BIS 1237[20] on cubic specimens (100 mm size). As per the specifications of ACI 544[21] the impact resistance of concrete specimens was calculated by carrying out the drop weight test. The water penetration test was carried out on 150 $\mathrm{mm}$ cubic specimens as per DIN 1048[22], which are expressed in terms of depth (mm). An analysis was carried out in the paper for embodied energy (EE) and carbon dioxide emission (ECO2). In this paper, the data for EE and ECO2 was taken from previous papers carried out by Mithun and Narasimhan[23], Sharma and Khan[24] and Siddique et al.[5].

Observing the results of the experimental study the authors concluded that, the maximum compressive strength was found with the replacement of $30 \%$ natural fine aggregate by Stone processing dust (SPD) and it is observed that up to $70 \%$ replacement the compressive strength is more than the nominal concrete.

The main purpose of increasing the compressive strength is the finer particle of stone dust having maximum particles of size is 


\section{International Journal of Engineering Applied Sciences and Technology, 2020 \\ Vol. 4, Issue 10, ISSN No. 2455-2143, Pages 411-413 \\ Published Online February 2020 in IJEAST (http://www.ijeast.com)}

less than 600 micron. Due to less voids and good bonding between cement and aggregate the modulus of elasticity of concrete improves up to $70 \%$ replacement of stone processing dust (SPD).

\section{A. Impact Resistance -}

The impact energy of the concrete is similar up to $40 \%$ replacement compare to control concrete and above $40 \%$ it is less than control concrete. If the replacement of stone processing dust (SPD) is more than $40 \%$ then it leads to increasing voids and due to its cracks easily developed and causes less impact energy.

\section{B. Abrasion Resistance -}

In concrete specimen, when stone processing dust (SPD) is replaced up to $20 \%$ gives a similar abrasion value as that of control concrete. While stone processing dust (SPD) is more than $20 \%$ that gives less abrasion resistance.

\section{Water Penetration -}

In this test the stone processing dust (SPD) is replaced up to $90 \%$ gives the lower water penetration depth value than the control concrete, also the replacement of $100 \%$ stone processing dust (SPD) gives a higher value and $30 \%$ gives the least value.

\section{Cost analysis for concrete mixes containing stone processing dust -}

The concrete mix having $100 \%$ stone processing dust was found to be most cost-effective with a cost reduction of $11.43 \%$ as compared to nominal concrete. However, considering the high-performance concrete mix having $30 \%$ stone processing dust gives $3.43 \%$ cost reduction.

\section{CONCLUSION}

Stone processing dust is the best alternative material use on behalf of natural river sand in concrete. Stone processing dust is the waste material which is hazardous to the living environment. Reduction or recycle of Stone processing dust as a partial replacement for concrete manufacture have a more influence on the environment which reduces the pollution and clean healthy environment.

Therefore, from the above study, we can conclude that different research can be done in the direction of partially replacing sand by reusing or introducing waste material as stone processing dust. By the use of nearby available stone processing dust as a partial replacement at the place of concrete ingredients, it can prove more cost-effective than nominal concrete and the problem of dumping of such waste produced by different quarries and industries is also get solved.
In this literature paper, the strength can be achieved by replacing natural river sand with stone processing dust and also improves some mechanical properties such as water penetration, impact test, and abrasion test. The final aim is to produce economical and eco-friendly concrete with all strength and desired properties which are achieved by nominal concrete ingredients.

\section{ACKNOWLEDGMENT}

We would like to express our sincere thanks to our researcher who gave us valuable information which is useful in my proposed paper work. We would also like to thank our publication.

\section{REFERENCE}

[1] T. Gupta, S. Kothari, S. Siddique, R. K. Sharma, S. Chaudhary, Influence of stone processing dust on mechanical, durability and sustainability of concrete, Construction and Building Materials 223 (2019) 918-927. A. A. Reddy and B. N. Chatterji, "A new wavelet based logo-watermarking scheme," Pattern Recognition Letters, vol. 26, pp. 1019-1027, 2005.

[2] D. Macedo, R. Mori Junior, L.S.L.S. Carvalho, and A.M.P. Mizusaki, Sustainability certification scheme for the dimension stone industry in Brazil: a proposal for an initiative based on the northwest region of Espírito Santo State, Brazil, J. Cleaner Prod. 182 (2018) 896-909. F. Gonzalez and J. Hernandez, " A tutorial on Digital Watermarking ", In IEEE annual Carnahan conference on security technology, Spain, 1999.

[3] S. Bai, Q. Hua, L.J. Cheng, Q.Y. Wang, T. Elwert, Improve sustainability of stone mining region in developing countries based on cleaner production evaluation: methodology and a case study in Laizhou region of China, J. Cleaner Prod. 207 (2019) 929-950.

[4] T. Gupta, S. Chaudhary, R.K. Sharma, Assessment of mechanical and durability properties of concrete containing waste rubber tire as fine aggregate, Constr. Build. Mater. 73 (2014) 562-574.

[5] S. Siddique, S. Chaudhary, S. Shrivastava, T. Gupta, Sustainable utilisation of ceramic waste in concrete: exposure to adverse conditions, J. Cleaner Prod. 210 (2019) 246-255.

[6] S. Siddique, S. Shrivastava, S. Chaudhary, T. Gupta, Strength and impact resistance properties of concrete containing fine bone china ceramic aggregate, Constr. Build. Mater. 169 (2018) 289-298.

[7] BIS 383, Coarse and, Fine Aggregate for Concrete Specification, Bureau of Indian Standards, New Delhi, India, 2016. 


\section{International Journal of Engineering Applied Sciences and Technology, 2020 \\ Vol. 4, Issue 10, ISSN No. 2455-2143, Pages 411-413 \\ Published Online February 2020 in IJEAST (http://www.ijeast.com)}

[8] H. Li, F. Huang, G. Cheng, Y. Xie, Y. Tan, L. Li, Z. Yi, Effect of granite dust on mechanical and some durability properties of manufactured sand concrete, Constr. Build. Mater. 109 (2016) 41-46.

[9] W. Shen, Y. Liu, Z. Wang, L. Cao, D. Wu, Y. Wang, X. $\mathrm{Ji}$, Influence of manufactured sand's characteristics on its concrete performance, Constr. Build. Mater. 172 (2018) 574-583.

[10] W. Shen, Z. Yang, L. Cao, L. Cao, Y. Liu, H. Yang, Z. $\mathrm{Lu}$, J. Bai, Characterization of manufactured sand: particle shape, surface texture and behavior in concrete, Constr. Build. Mater. 114 (2016) 595-601.

[11] P. Nanthagopalan, M. Santhanam, Fresh and hardened properties of selfcompacting concrete produced with manufactured sand, Cem. Concr. Compos. 33 (3) (2011) 353-358.

[12] X. Ding, C. Li, Y. Xu, F. Li, S. Zhao, Experimental study on long-term compressive strength of concrete with manufactured sand, Constr. Build. Mater. 108 (2016) 6773.

[13] T. Ji, C.-Y. Chen, Y.-Z. Zhuang, J.-F. Chen, A mix proportion design method of manufactured sand concrete based on minimum paste theory, Constr. Build. Mater. 44 (2013) 422-426.

[14] B. Li, G. Ke, M. Zhou, Influence of manufactured sand characteristics on strength and abrasion resistance of pavement cement concrete, Constr. Build. Mater. 25 (10) (2011) 3849-3853.

[15] B. Menadi, S. Kenai, J. Khatib, A. Aït-Mokhtar, Strength and durability of concrete incorporating crushed limestone sand, Constr. Build. Mater. 23 (2) (2009) 625633.

[16] R. Cepuritis, S. Jacobsen, B. Pedersen, E. Mørtsell, Crushed sand in concrete- effect of particle shape in different fractions and filler properties on rheology, Cem. Concr. Compos. 71 (2016) 26-41.

[17] BIS 10262, Concrete Mix Proportioning - Guidelines, Bureau of Indian Standards, New Delhi, 2009.

[18] BIS 10262, Concrete Mix Proportioning - Guidelines, Bureau of Indian Standards, New Delhi, 2009.

[19] ASTM C469, Standard Test Method for Static Modulus of Elasticity and Poisson's Ratio of Concrete in Compression, ASTM International, West Conshohocken, PA, 2014.

[20] BIS 1237, Specification for Cement Concrete Flooring Tiles, Bureau of Indian Standards, New Delhi, India, 2012.

[21] ACI 544.2R-89, Measurement of Properties of Fiber Reinforced Concrete, ACI, West Conshohocken, PA, 1999.
[22] DIN 1048, Testing Concrete: Testing of Hardened Concrete Specimens Prepared in Mould, Part 5, Deutsches Institut fur Normung, Germany, 1991.

[23] B. Mithun, M. Narasimhan, Performance of alkali activated slag concrete mixes incorporating copper slag as fine aggregate, J. Cleaner Prod. 112 (2016) 837- 844.

[24] R. Sharma, R.A. Khan, Sustainable use of copper slag in self compacting concrete containing supplementary cementitious materials, J. Cleaner Prod. 151 (2017) 179192.

[25] C. Jiang, W. Guo, H. Chen, Y. Zhu, C. Jin, Effect of filler type and content on mechanical properties and microstructure of sand concrete made with superfine waste sand, Constr. Build. Mater. 192 (2018) 442-449.

[26] A. Halicka, P. Ogrodnik, B. Zegardlo, Using ceramic sanitary ware waste as concrete aggregate, Constr. Build. Mater. 48 (2013) 295-305.

[27] E. Ganjian, M. Khorami, A.A. Maghsoudi, Scrap-tyrerubber replacement for aggregate and filler in concrete, Constr. Build. Mater. 23 (5) (2009) 1828-1836.

[28] BIS 8112, Ordinary Portland Cement, 43 GradeSpecifications, Bureau of Indian Standards, New Delhi, India, 2013. 